\title{
Diagnostic Value of Plasma Amylase, especially after Gastrectomy
}

\author{
G. K. McGOWAN,* B.A., в.M., в.CH. ; M. R. WILLS, $†$ M.B., СH.в.
}

Brit. med. F., 1964, 1, 160-162

The plasma-amylase level is almost invariably raised at the beight of an attack of acute pancreatitis. However, the diagmostic value of this is limited by the occasional finding of equally high levels in patients with acute abdominal conditions which are not primarily acute pancreatitis. In our experience such "false-positive" findings have been commonly associated with a history of gastrectomy. In order to study this relationship we have reviewed, for the 10-year period January 1952 to December 1961, the 119 patients whose plasma-amylase levels were found to be above 1,000 units (Somogyi)/100 ml. Of these, 113 had acute abdominal symptoms resembling those of acute pancreatitis.

\section{Method of Amylase Estimation}

Plasma amylase was estimated by the method of Somogyi (1938) as described by King (1946). In order to exclude false high results due to bacterial decomposition of the starch substrate the latter has been measured in 2-ml. quantities into rubber-capped tubes, sterilized by heating to $60^{\circ} \mathrm{C}$. for one hour on three successive days, and stored in the refrigerator. Where the amylase level has been high enough to reduce the digestion time below four minutes the estimation has been repeated after diluting the plasma with saline. Precautions were taken to avoid contamination with saliva. We find that hospital patients without obvious pancreatic disease, including those who have undergone abdominal operations, have levels of amylase in the plasma up to 300 units $/ 100 \mathrm{ml}$. We accept a level of 1,000 units $/ 100 \mathrm{ml}$. as the minimum necessary to support a Jiagnosis of acute pancreatitis.

\section{Subjects Investigated}

Primary acute pancreatitis is best treated conservatively. If the diagnosis of acute pancreatitis is made wrongly, the error will not be serious if the appropriate treatment for the condition actually present is conservative also. If, however, the condition is one which demands urgent surgery, the mistake is likely to be fatal for the patient. The main clinical value of the amylase :est lies in the differentiation of these two groups, and we have thercfore classified the patients with high plasma-amylase levels into two major groups: (1) 91 patients with primary acute pancreatitis or some other condition (including secondary pancreatitis) not requiring urgent surgery, and (2) 22 patients with acute abdominal conditions (also including secondary pancreatitis) which usually require urgent surgery (see Table I). In fact, several patients in group 1 were operated on, and several in group 2 were not.

\section{Group 1}

A. In the first subgroup of 90 patients with acute pancreatitis the classical syndrome and course of the disease were seen. In 36 the disease was " primary," though 42 had a history suggesting disease of the biliary tract ; plasma-amylase levels ranged up to 16,000 , and confirmation of the diagnosis was obtained at

\footnotetext{
- Consultant Chemical Pathologist, United Bristol Hospitals.
}

+ Senior Registrar in Chemical Pathology, United Bristol Hospitals. laparotomy in 18 ( 5 during the acute attack, 13 later) and at necropsy in five. In another three patients the pancreatitis followed gall-bladder surgery ; these developed acute abdominal symptoms within 70 hours of the operation, at which the common bile-duct had been explored in each case, and the initial plasma-amylase levels were $9,000,4,000$, and 1,050 units $/ 100$ $\mathrm{ml}$. The remaining patient was admitted as an acute abdominal emergency with a plasma amylase level of 3,200 units $/ 100 \mathrm{ml}$., and made a good recovery on conservative treatment. Increasing jaundice led to laparotomy five weeks later, when carcinoma of the ampulla of Vater was discovered; no mention was made of the pancreas in the operation notes.

TABle I.-Classification of Patients With Acute Abdominal Symptoms and a Plasma-amylase Level of More than 1,000 Units $/ 100 \mathrm{ml}$.

Group 1. Patients not requiring urgent surgery (91)

A. With acute pancreatitis

$\begin{array}{llllll}\text { "Primary" } \ldots & . & . & \ldots & \ldots & 8\end{array}$

After biliary-tract surgery $\because$ with carcinoma of the ampulla of 3

B. Without pancreatitis

Thrombosis of inferior vena cava $\cdots$

Group 2. Patients requiring urgent surgery (22)

A. Without a history of gastrectomy

Perforated peptic ulcer

Biliary peritonitis..
Thrombosis of superior mesenteric artery

Ruptured aortic aneurysm

Traumatic pancreatitis associated with damage to other abdominal viscera

B. With a history of gastrectomy

90

(n) (see text and Table II)

We have not encountered any proved case of primary acute pancreatitis in which the plasma-amylase level has not been raised at the height of the attack.

B. The second subgroup, in which pancreatitis was absent, contains only one patient who, like those in subgroup A, had a high amylase with abdominal symptoms and did not require operation. She was admitted with severe epigastric pain and circulatory insufficiency, and on the fourth and fifth days her plasma-amylase levels were found to be 1,400 and 1,800 units/ $100 \mathrm{ml}$. She died on the sixth day, and necropsy revealed thrombosis of the inferior vena cava with involvement of the hepatic veins and venous infarction of the liver; the pancreas was macroscopically and microscopically normal.

\section{Group 2. Patients Requiring Urgent Surgery}

This group comprises 22 patients whose high plasma-amylase levels can be regarded as serious "false positives" in the sense that they could have led to the wrong decision not to operate. A history of gastrectomy was obtained in no fewer than 12 .

\section{A. Those Without Gastrectomy}

Four were suffering from a perforated peptic ulcer with generalized peritonitis, and initial plasma-amylase levels were $2,600,2,000,2,000$, and 1,600 units $/ 100 \mathrm{ml}$. In view of the overall clinical findings three were subjected to laparotomy, and two of these survived. The fourth patient, who was not operated on, died. In all four the pancreas was macroscopically normal. 
Two patients had biliary peritonitis; laparotomy was performed in each, and revealed a small perforation in an inflamed gall-bladder; both survived. Initial plasma-amylase levels were 2,000 and 3,200 units $/ 100 \mathrm{ml}$. In one the pancreas was described as normal, whereas in the other it showed some enlargement and oedema but without fat necrosis.

One patient died within 12 hours of the onset of an attack of diarrhoea and severe abdominal pain with a plasma-amylase level of 2,000 units $/ 100 \mathrm{ml}$. Necropsy revealed thrombosis of the superior mesenteric artery and a pancreas which appeared normal.

One patient with severe abdominal pain and a plasmaamylase level of 1,200 units $/ 100 \mathrm{ml}$. died soon after admission, having been severely oliguric for at least 30 hours. At necropsy there was a ruptured aneurysm of the abdominal aorta, and the pancreas was normal in the gross and on section.

Two patients had pancreatic lacerations as a result of abdominal trauma which had also ruptured the small intestine, and initial plasma-amylase levels were 8,000 and 1,100 units/ $100 \mathrm{ml}$. Laparotomy was performed in each case and both survived.

\section{B. Part-gastrectomy "False-positive" Cases (12)}

These cases are summarized in Table II. The gastrectomy was a Polya in 10, while in the other two it was of the Rouxen-Y and Billroth I variety.

There was evidence of afferent-loop obstruction at laparotomy or necropsy in 10 of the patients. In nine of these the gastrectomy was of the Polya type ; in the tenth it was of the Rouxen-Y type. Six of the 10 had a leak from the duodenal stump or from the anastomosis, with generalized peritonitis. The interval between operation and afferent-loop obstruction was very variable: in four it was only two days, but in two it was as long as four and five years. The pancreas was described as normal in four (confirmed histologically in only one) and as being superficially inflamed owing to the peritonitis in another four. In two cases there is no record of the appearance of the gland.

In one of the two remaining cases (No. 2) there was a generalized peritonitis causing death five days after a Polya gastrectomy. At necropsy no perforation or other cause of the peritonitis was found, and the pancreas appeared normal ; there is no record of the state of the afferent loop.

In the twelfth case (No. 1) the patient became shocked, with severe abdominal pain, 24 hours after a Billroth I gastrectomy,

TABle II.-Post-gastrectomy Patients With Plasma-amylase Levels Over 1,000 Units $100 \mathrm{ml}$. (Each Group in Chronological Order)

\begin{tabular}{|c|c|c|c|c|c|c|c|c|c|}
\hline $\begin{array}{l}\dot{0} \\
\dot{z} \\
y\end{array}$ & 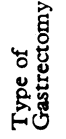 & 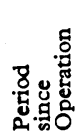 & 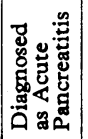 & 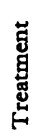 & 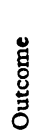 &  & 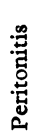 & 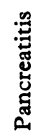 &  \\
\hline
\end{tabular}

With Symptoms Resembling Acute Pancreatitis

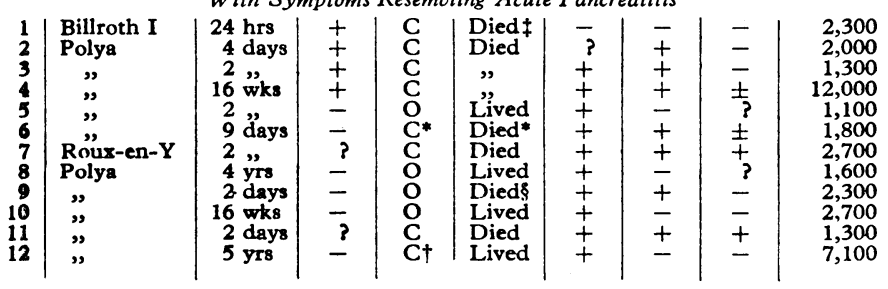

\begin{tabular}{|c|c|c|c|c|c|c|c|c|c|}
\hline & & Vithout & $n p t c$ & Rese & ling $A c$ & $\mathrm{~Pa}$ & atitis & & \\
\hline $\begin{array}{l}13 \\
14\end{array}$ & $\begin{array}{c}\text { Billroth II } \\
\text { I }\end{array}$ & $\begin{array}{l}1 \text { day } \\
1, y\end{array}$ & $\dot{t}$ & $\stackrel{\mathrm{C}}{\mathrm{C}}$ & $\begin{array}{l}\text { Lived } \\
\text { ", }\end{array}$ & $\overline{-}$ & $=$ & $+?$ & $\begin{array}{l}4,000 \\
1,300\end{array}$ \\
\hline
\end{tabular}

* Unfit for operation

† Correctly diagnosed as mild uncomplicated afferent-loop obstruction, relieved by subsequent "cold" operation.

$\ddagger$ Cause of death not found at necropsy.
\$ Died of stroke. and died on the third day. Necropsy revealed nothing to account either for the high amylase level or for the fatal outcome.

Our results confirm the generally held view that the plasmaamylase level is raised in almost every case of pancreatitis in the acute stage, but that such levels cannot be used as the sole criterion for a decision not to operate, because equally high values are found, with or without inflammation of the pancreas, in other conditions which require urgent surgery. Such falsepositive results occurred in 22 out of 113 cases, or just under $20 \%$ (Table I, group 2).

Twelve of these false positives were found in patients with a history of gastrectomy performed from one day to five years previously. In nearly all cases the complication appears to have been an afferent-loop obstruction following a Polya or Rouxen-Y operation, which is believed to raise the plasma amylase by back-pressure from the distended loop acting up the pancreatic duct (Olson et al., 1960). One case had undergone a Billroth I gastrectomy, and here the plasma-amylase level was probably raised as a result of damage during mobilization of the duodenum, either to the gland or its accessory ducts (Millbourn, 1949) or possibly to its blood supply (Burton et al., 1957). We have records of two other patients (Cases 13 and 14 in Table II) on whom a Billroth II and Billroth I gastrectomy respectively were performed ; because at operation the gland was thought to have been damaged in one case and to be chronically inflamed in the other, plasma-amylase levels were determined 24 hours after operation and found to be 4,000 and 1,300 units/ $100 \mathrm{ml}$. Neither had symptoms suggestive of acute pancreatitis, but at operation there was evidence of chronic pancreatitis in Case 14.

\section{Discussion}

Several cases of afferent-loop obstruction simulating acute pancreatitis are recorded in the literature. The complication seems to be most commonly associated with the Polya gastrectomy and its variants, but is not confined to that operation. Perry (1954) described the case of a patient whose symptoms developed on the thirteenth day after a Hofmeister gastrectomy with a plasma-amylase level of 63 Myer-Killian units (normal, up to 25); he was treated conservatively for eight days and died after a second operation. At necropsy peritonitis and a mild secondary pancreatitis were found. A patient recorded by Thal and Perry (1956) developed symptoms with a plasma amylase of 2,000 units $/ 100 \mathrm{ml}$. two months after a Polya gastrectomy ; after conservative treatment for seven days he died of peritonitis due to perforation of the afferent loop, and his pancreas was found to be normal at necropsy. Ballon and Niloff (1959) described two cases after total and partial gastrectomy respectively ; plasma-amylase levels were 1,090 and 838 $\mathrm{mg}$. $/ 100 \mathrm{ml}$. (units not defined). On the fifth day laparotomy was performed on one ; but both died of peritonitis, and at necropsy both glands were normal. Howard (1960) mentioned briefly two patients who developed the same syndrome years after gastrojejunostomy and were treated conservatively, both dying from rupture of the duodenum. Hinshaw et al. (1960) reported four cases, all with plasma amylase levels of over 1,000 units $/ 100 \mathrm{ml}$; in three the operation was specified as Billroth II gastrectomy. A laparotomy was performed on three, of whom two survived ; the third died, as did the patient not operated upon.

It is evident from the literature cited that the mortality is high if the patient is not operated on promptly. Our experience has been the same (Table II).

The first four false positives in this group included three cases of peritonitis. All were diagnosed as acute pancreatitis and treated conservatively, and all these patients died.

On subsequent occasions a history of gastrectomy was sought whenever a high amylase was recorded in the laboratory, and if 
such a history was present the surgeon was advised that the level should not be taken as evidence of uncomplicated acute pancreatitis. In the remaining eight cases a correct diagnosis was made in six and laparotomy was performed on four (Cases 5, 8,9 , and 10 ), of which three survived and one died of a stroke; of the two not operated on, one (Case 12) was diagnosed as a mild uncomplicated afferent-loop obstruction and treated conservatively with success, while the other (Case 6) was considered unfit for operation and died. In the two remaining cases (Nos. 7 and 11) there was uncertainty about accepting this interpretation of the amylase level; in one there had been operative trauma to the pancreas, and both showed considerable initial improvement on intravenous fluids and antibiotics; operation was withheld, and both died of peritonitis.

We believe that correct interpretation of the amylase level would have led to operation in six patients who died, and might have reduced the overall mortality from eight to three.

Our interpretation of high amylase levels might have to be qualified if it were common for uncomplicated acute pancreatitis to occur after gastrectomy. We are not aware of such an occurrence in this hospital during the period under review. Warren (1951) described five cases, but in none was a plasmaamylase level of more than 1,000 units/ $100 \mathrm{ml}$. recorded, and in two there was perforation of the duodenal stump, supposedly the result of the pancreatitis ; in one other case (fatal) there was no confirmation of the diagnosis by laparotomy or necropsy. Dunphy et al. (1953) recorded three cases, but again none had a plasma-amylase level of over 1,000 units $/ 100 \mathrm{ml}$., and two were found at necropsy to have peritonitis in the absence of any obvious leak. Burton et al. (1957) described five cases, but the only one with a plasma-amylase level of more than 1,000 units/ $100 \mathrm{ml}$. was in fact suffering from biliary peritonitis due to perforation of the common bile-duct; of the others, one had acute generalized peritonitis without any apparent leak. These published cases do not conflict with our thesis that a high plasma amylase after a gastrectomy is not likely to be due to uncomplicated acute pancreatitis.

The results in false positives without a history of gastrectomy were more favourable, because in 7 of the 10 cases the diagnosis of pancreatitis was not accepted on clinical grounds, and operations were performed with only one death. The three cases not operated on were one of perforated peptic ulcer, one of ruptured abdominal aortic aneurysm, and one of thrombosis of the superior mesenteric artery; all these patients died, but the second and third might well have died even with an operation.

\section{Summary and Conclusions}

We report a review of 113 patients with acute abdominal symptoms whose plasma-amylase level was more than 1,000 units (Somogyi) $/ 100 \mathrm{ml}$. Of these, 91 ( $81 \%$ ) were suffering from conditions which did not require urgent surgery; 90 had acute pancreatitis, which was " primary" in 86.

The remaining $22(19 \%)$ patients were suffering from conditions which required urgent surgery, and just over half of this group had a history of gastrectomy. The complication of gastrectomy responsible for the patient's condition was usually afferent-loop obstruction, and perforation with generalized peritonitis was common; mortality was high if operation was not undertaken.

We conclude that whenever a high plasma-amylase level is found in association with an acute abdominal condition a history of gastrectomy should be sought. If it is present, the amylase level should be discounted as evidence of uncomplicated acute pancreatitis. Exclusion of these cases should considerably improve the practical value of plasma-amylase levels in the differential diagnosis of primary acute pancreatitis.

We are very grateful to the surgeons of the United Bristol Hospitals for permission to publish details of the patients admitted under their care.

\section{REFERENCES}

Ballon, H. C., and Niloff, P. H. (1959). Canad. med. Ass. F., 80, 339. Burton, C. C., Eckman, W. G., jun., and Haxo, J. (1957). Amer. F. Surg. 94, 70.

Dunphy, J. E., Brooks, J. R., and Ackroyd, F. (1953). New Engl. 7. Med. 248, 445 .

Hinshaw, D. B., Carter, R., Baker, H. W., and Wise, R. A. (1960). Ann. Surg., 151, 600 .

Howard, J. M. (1960). Surgical Diseases of the Pancreas, edited by J. M. Howard and G. L. Jordan. Pi man, London.

King, E. J. (1946). In Micro-Analysis in Medical Biochemistry.

Millbourn, E.' (1949). Acta chir. scand., 98, 1.

Olson, C. A., Hinshaw, D. B., and Carter, R. (1960). Surg. Gynec. Obstet., 110, 66.

Perry, T., un. (1954). Ann. Surg., 140, 119.

Somogyi, M. (1938). 7. biol. Chem., 125, 399.

Thal, A., and Perry, J. F., un. (1956). Ann. Surg., 143, 266.

Warren, K. W. (1951). Surgery, 29, 643.

\title{
Encephalitis Syndrome of Lymphocytic Choriomeningitis Virus Infection
}

\author{
K. K. NAYAK,* M.B., M.R.C.P. ; S. O. WALLER, † M.B., B.S., D.C.P. ; G. KUPPUSWAMY,‡ M.B., M.R.C.P., D.T.M.\&H.
}

Rivers and Scott (1935) recovered the lymphocytic choriomeningitis (L.C.M.) virus from the cerebrospinal fluid of two patients with benign aseptic meningitis. The virus was so named because in experimental animals it produced inflammatory lesions of the choroid plexus.

L.C.M. virus is known to occur naturally in dogs, monkeys, guinea-pigs, and house mice, and has been isolated from nasal secretions, execretory and other material such as urine, faeces, and semen of animals (Adams, 1960).

Our knowledge of the natural history of infection with the L.C.M. virus in man is scanty. It is known to cause the syndrome of aseptic meningitis, fulfilling Wallgren's (1925) criteria; these are an acute onset of febrile illness with signs and symptoms of meningeal involvement, pleocytosis, and bacteriologically sterile cerebrospinal fluid. It is also recognized that it can cause a grippe-like illness in laboratory workers. Smadel et al. (1942) reported two fatal cases of infection with the L.C.M. virus in laboratory workers. During the illness both patients showed signs and symptoms of lower respiratory infection and patches of pneumonia were reported at necropsy. Lumbar puncture was not performed in either case during life as clinically there appeared to be no indication for it. L.C.M. virus was isolated from the blood and brain tissue in one case and from pulmonary tissue in the other.

\footnotetext{
Colonel, A.M.C. ; Professor of Medicine, Armed Forces Medical College, Poona. Indid.

Cieutenan-Colonel A M.C. Virologist and Associate Professor of Pathology, Armed Forces ifedical College, Poona

Armed Forces Medical College, Poona Forces Medical Collsze, Poona, India.
} 